\title{
CFD multiphase modelling of the acetone condensation and evaporation process in a horizontal circular tube
}

\section{Hayder I. Mohammed, Donald Giddings, Gavin S. Walker and Henry Power}

\begin{abstract}
With increasing demands on energy efficiency, the use of low grade waste heat using vapour absorption refrigeration systems (VARS) are receiving renewed interest. One idea is to use the combination of acetone and zinc bromide as the salt solution, which allows use of temperatures in the order of $10 \mathrm{~s}$ of ${ }^{\circ} \mathrm{C}$ above ambient conditions. This work numerically models acetone phase change in the evaporator and condenser in order to indicate how improvements can be made in these components of the system. ANSYS ${ }^{\circledR}$ Fluent finite volume method CFD is used to produce volume of fluid (VOF) and mixture multiphase flow models to investigate the evaporation and the condensation of acetone in a horizontal circular tube. Different velocities and temperatures were taken in each process to explore the effect of these variables in the system. A user defined function (UDF) is used to calculate the volume fraction of the phases. For the evaporation case, the heat transfer coefficient increases with increasing velocity and the temperature difference between the inlet flow and the wall, as expected. The mass transfer rate decreases with increasing the flow rate or decreasing the wall temperature, from 0.045 $\mathrm{kg} / \mathrm{m}^{3} . \mathrm{s}$ at $0.01 \mathrm{~m} / \mathrm{s}$ to $0.016 \mathrm{~kg} / \mathrm{m}^{3} . \mathrm{s}$ at $0.06 \mathrm{~m} / \mathrm{s}$ and it drops from 0.044 to $0.023 \mathrm{~kg} / \mathrm{m}^{3} . \mathrm{s}$ by changing the temperature just from 300 to $298 \mathrm{~K}$. This demonstrates a reduction in specific heat transfer to the liquid despite the higher wall heat transfer coefficient. In the condenser, vapour quality decreases along the tube as liquid acetone is created with reduced flow rate. Vapour volume fraction at the outlet section drops from 0.74 to 0.168 by increasing the ingoing velocity from 0.01 to $0.06 \mathrm{~m} / \mathrm{s}$. Increasing the rate of condensation will increase the liquid in the evaporator, which increase the evaporation rate then increase the performance of the VARS. This demonstrates the importance of controlling the temperature and the flow rate in the VARS for generate more refrigerants.
\end{abstract}

\section{Keywords}

Acetone, Condensation, Evaporation, CFD, Heat transfer, Mass transfer, pipe flow, Phase change.

\section{Nomenclature}

t Time $(\mathrm{s})$

v Velocity $(\mathrm{m} / \mathrm{s})$

p Pressure $(\mathrm{N} / \mathrm{m} 2)$

g Gravity $(\mathrm{m} / \mathrm{s} 2)$

F Body force $(\mathrm{N})$

$\mathrm{T}$ Temperature $(\mathrm{K})$

\section{Greek letters}

$\begin{array}{ll}\rho & \text { Density }\left(\mathrm{kg} / \mathrm{m}^{3}\right) \\ \mu & \text { Viscosity }(\mathrm{kg} / \mathrm{m} . \mathrm{s}) \\ \varphi & \text { Volume fraction } \\ \sigma & \text { Turbulent Prandtle number } \\ \varepsilon & \text { Dissipation rate } \\ \beta & \text { Coefficient of thermal expansion }\end{array}$




$\begin{array}{cl}\mathrm{S} & \text { Modulus of the mean rate-of-strain } \\ & \text { tensor } \\ \mathrm{x} & \text { Axial dimension (m) } \\ \mathrm{G} & \text { Generation of turbulence K.E } \\ \mathrm{C} & \text { Constant } \\ \mathrm{K} & \text { Kinetic energy (j) } \\ \mathrm{Pr} & \text { Prandtel number } \\ M & \text { Mach number } \\ \mathrm{E} & \text { Energy (j) } \\ E_{y 1} & \text { Transition sources } \\ P_{y 1} & \text { Transition sources } \\ P_{y 2} & \text { Destruction source } \\ E_{y 2} & \text { Destruction source } \\ \mathrm{m} & \text { Mass (kg) } \\ \mathrm{h} & \text { Film hight (m) } \\ \mathrm{h}_{\mathrm{t}} & \text { Heat transfer coefficient } \\ \mathrm{h}_{\mathrm{m}} & \text { Mass transfer cofficent } \\ \mathrm{L} & \text { Latent heat associated }\end{array}$

$\begin{array}{ll}\gamma & \text { Wall distance }(\mathrm{m}) \\ \Omega & \text { Vorticity }(1 / \mathrm{s}) \\ \nabla & \text { Surface gradient operator }\end{array}$

\section{Subscripts}

$m \quad$ Mixture

k Phase

dr Drift

f Film

$\mathrm{t}$ Turbulence

p Primary phase

q Secondary phase

1 Liquid

v Vapour

s Source

w Wall

sat Saturated

\section{Introduction}

Low grade waste heat (heat produced by system due to a mechanical or chemical processes that use energy) from small industrial and micro-generation plants can be used to generate cooling using vapour absorption refrigeration systems which are suitable for use with low temperature difference between waste heat and ambient temperature. VARS rely on effective evaporation and condensation processes to enhance performance. One particular VARS of recent interest for low grade heat systems uses acetone and zinc bromide salt solution [1-4]. Most existing research on VARS concentrates on $\mathrm{NH}_{3} / \mathrm{H}_{2} \mathrm{O}$ and $\mathrm{H}_{2} \mathrm{O} / \mathrm{LiBr}$ for the case where higher grade heat is available. Macriss et al. [5] provide a survey of absorption system fluids; they suggest that there are about 40 refrigerants and around 200 absorbents which can be used in absorption systems. $\mathrm{H}_{2} \mathrm{O} / \mathrm{LiBr}$ is used in many literatures for various purposes described in the following [6-12].

There are no studies found related with the heat and mass transfer for acetone as a refrigerant; however, it has been done for other liquids such as water. For example, Walter et al. [13] studied the heat and mass transfer of the condensation process of water in a square cross section channel, also, there are different studies related to the heat and mass transfer through the evaporation and boiling processes [14-16]. The concept of condensation mass transfer was modelled first by Colburn and Hougen [17]. In their study, the mass concentration gradient through a non-condensable gas layer controlled the mass transfer in the condensation process. They defined the heat transfer procedure as the sum of sensible heat and latent heat flows. Li [18] used a computational fluid dynamics (CFD) simulation to study the condensation of water vapour as a turbulent flow in a vertical cylindrical tube. He found that the average axial velocity drops quickly as water vapour is condensed, because the density of the gas mixture increases across the condenser tube and along the condenser. 
Padin and Soares [19] studied CFD modelling of steam condensing in industrial tubes. They observed that there was a linear variation of the vapour concentration from the inlet of the pipe along the axial distance when the inlet velocity in the range of $4-5 \mathrm{~m} \cdot \mathrm{s}^{-1}$ with two different wall temperature (293.15 K and 343.15 K). Sun et al. [20] modelled condensation and evaporation phase change for water using ANSYS ${ }^{\circledR}$ Fluent based on the volume of fluid (VOF) model. Their simulation showed good agreement with the classical analytical results, their model is suitable for the case with saturated and unsaturated vapour. They developed a phase change model based on the calculation of the heat source term through a UDF code, and obtained a grid independent and accurate outcome, which has been verified by two-phase flow and heat transfer experiments.

Mimouni et al. [21] use NEPTUNE CFD code for wall steam condensation with varying homogeneous flow in a nuclear-pressurized water reactor (PWR). They found a large amount of steam and hydrogen gas is released within the dry containment of PWR. Their expectation of axial velocity did not agree in some cases because of the turbulence modelling. Nabati [22] investigated numerically the condensation of water from a flue gas with high $\mathrm{CO}_{2}$ content. They found that the total heat transfer rate depends on the inlet velocity and temperature and that the heat transfer coefficient decreases as the $\mathrm{CO}_{2}$ mass fraction increases in the constant wall temperature case. Their results could be use in the condenser's design for oxi-fuel power plants. Hiller and Swift [23] studied the condensation in a steadyflow thermoacoustic refrigerator. They found that the liquid condensate does not show an effect to the oscillating thermoacoustic variables, which can be described by ideal-gas equations, but the condensing water is a large thermal load on the refrigerator. Laguerre et al. [24] studied the water evaporation and condensation in a domestic refrigerator loaded by wet product. They state that the numerical simulation which gives information on temperature, velocity and humidity fields may be used to evaluate risk during food preservation in domestic refrigerator.

Heat and mass transfer during the evaporation process has received much attention. Gao et al. [25] simulated flow and boiling heat transfer in a horizontal tube using the mixture approach and adding user-defined source term functions of mass transfer and energy transfer on phase boundary. Their results show that the heat transfer is enhanced by increasing the velocity and they realised that the superheat of the wall is one of the main factors affecting the heat transfer. Trujillo et al. [26] used Fluent CFD to model the heat and mass transfer process during evaporation of water in a circular tube. They found that the RNG к- $\varepsilon$ model using the enhanced wall treatment, taking into consideration the effect of radiation, fits better the experimental data in the case when the wall temperature is higher than the fluid temperature. The CFD model showed that at low Reynolds numbers when the radiative heat is considered the relation $h_{\downarrow} / h_{m} C_{p}$ ( $h$ : heat transfer coefficient, $h_{m}$ : mass transfer coefficient and $C_{p}$ : specific heat capacity) is not constant around the cylinder.

Vik and Reif [27] implemented an improved evaporation model in Fluent based on the friction velocity. They found that the normalised evaporation rate is dropped with time and that the evaporation rate is $4.321 \times 10^{-11} \mathrm{~kg} / \mathrm{s}$ for RANS model and $4.01 \times 10^{-11} \mathrm{~kg} / \mathrm{s}$ for the LES model; however, the 
evaporation rate calculated analytically was $4.12 \times 10^{-11} \mathrm{~kg} / \mathrm{s}$. Yang et al. [28] investigated numerically and experimentally the two-phase flow during boiling of refrigerant R141B in a coiled tube. They found that the flow velocity is strongly dependent on the phase distribution and both the vapour and liquid interface and the flow rate had a great influence on the variation of the pressure drop and vapour volume fraction.

Falling film heat transfer were studied experimentally in different applications with conflicting results. For example, several studies [29-31] stated that with increasing the velocity, the heat transfer coefficient decreases first, and after specific value of velocity it starts increase. as Otherwise, according to $[32,33]$, the heat transfer coefficient always increasing with the velocity. The last two studies also present that for completely wetted surfaces in strictly convective conditions, the heat flux does not affect the heat transfer coefficient and the convective heat transfer coefficient increases with the liquid temperature. Yang and Shen [34] state that with increasing of the heat flux, the heat transfer coefficient increases. According to Parken [33], Armbruster and Mitrovic [35], it appears that the liquid temperature effect is strongly causing to the decrease of viscosity, consequently, dropping in the film thickness.

Vapour absorption refrigeration is dependent on the condensation and evaporation processes on the refrigerant side of the process. In the case of the acetone zinc bromide system, pure acetone is the refrigerant fluid, which is not represented in the literature for heat transfer processes for the particular fluid or at flow rates encountered. Therefore this paper presents a CFD representation of the condensation and evaporation of acetone in a single tube element of a heat exchanger using the volume of fluid (VOF) model for condensation and the mixture model for evaporation. A user defined function (UDF) code developed by Lee [36] in 1979 and written in the C language was used for the mass transfer and the phase change. The effect of varying wall and inlet temperatures and different inlet velocities of the liquid are explored in order to identify how the heat and mass transfer improve.

\section{Numerical method and Boundary condition}

\section{Geometry and Grid}

A representative horizontal pipe (200mm length and $15 \mathrm{~mm}$ diameter) was used to simulate both the evaporator and condenser heat exchanger elements. All the simulations were carried out with the commercial code Ansys ${ }^{\circledR}$ Fluent version 15.0.

In the evaporation process, a multiphase mixture flow with the standard $\mathrm{k}-\varepsilon$ model was used, the range of liquid inlet velocities were taken $(0.005,0.01,0.02,0.04$ and $0.06 \mathrm{~m} / \mathrm{s})$, i.e. the mass flux range was $(2.8-34 \mathrm{~g} / \mathrm{s})$ with a constant inlet temperature of $294 \mathrm{~K}$, consistent with the flow conditions defined by Ajib and Karno [1]. The condition of the acetone in the tube was saturation temperature 296 $\mathrm{K}$ at 0.22 bar. The outlet was considered as the outflow condition because the details of the flow velocity and the pressure were unknown. The wall temperature was taken as 298 and $300 \mathrm{~K}$ in separate cases. 
Figure 1-a shows a 2D scheme of the computational domain and the boundary conditions adopted for the evaporation process.

In the condensation process, the flow was considered to be steady state with a VOF approach and the effect of turbulence was taken into account using the transition SST (Shear Stress Transport) model, which is based on the coupling of the SST k-omega transport equations with two other transport equations, one of the intermittent and one for the transition onset criteria, in terms of momentumthickness Reynolds number. The Eulerian wall film, which can predict the creation and flow of thin liquid layers on the surface is activated and the surface tension of the acetone used in this process was $0.025 \mathrm{~N} / \mathrm{m}$ [37]. Different inlet velocities of the acetone saturated vapour were taken $(0.01,0.03,0.05$, 0.08 and $0.1 \mathrm{~m} / \mathrm{s}$ ) with the mass flux varying between $0.005-0.05 \mathrm{~kg} / \mathrm{m}^{2} . \mathrm{s}$, and inlet temperature 311 and $312 \mathrm{~K}$. The outlet was considered as the pressure outlet condition and the wall temperature was taken as 294 and $290 \mathrm{~K}$ in two separate cases with saturation temperature $310 \mathrm{~K}$ (saturation temperature of acetone at 0.28 bar) as shown in Figure 1-b. The pressure of the condensation is assumed higher than the evaporator because in the VARS the condensed fluid pass to the evaporator through the expansion valve which decreases the pressure.

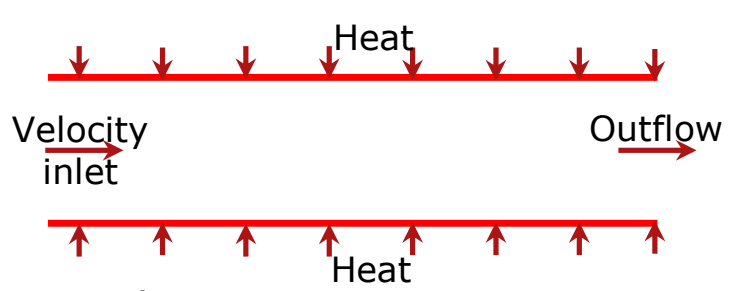

a)

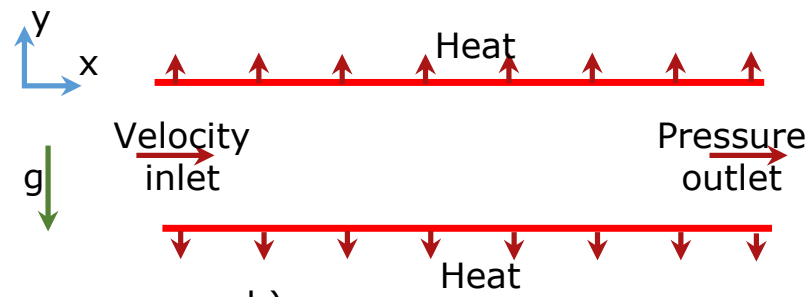

b)

Figure 1. 2D scheme of the computational domain and the boundary conditions adopted. The $z$ coordinate is out of plane. a) Evaporation process and b) Condensation process.

Different Grid densities were taken for each process and by considering the running time and the accuracy of the results are shown in table 1 . The mesh configurations for both of evaporation and condensation processes are shown in Figure 2. Figure 2-a presents the evaporator mesh (number of divisions along the tube is 121 and the maximum element length is $1.5 \times 10^{-4} \mathrm{~m}$ ). Figure 2-b presents the condenser mesh (number of divisions along the tube is 121 , maximum element length is $2.4 \times 10^{-4} \mathrm{~m}$ and the first layer height is $2 \times 10^{-6} \mathrm{~m}$ ). Because a very thin layer of the liquid was created on the wall, the mesh was refined at the wall as much as possible. Different meshes for the tube cross section were taken; when the first layer height was less than $2 \times 10^{-6} \mathrm{~m}$, the software could not run because of a very high aspect ratio, therefore, the thinnest first layer height is $2 \times 10^{-6} \mathrm{~m}$. The time step of the solver was $0.01 \mathrm{~s}$ for both of the processes, resulting in a flow travel of between 0.005 and $0.1 \mathrm{~cm}$ between timesteps for the various cases. 
Table 1 Mesh independence study for both evaporation and condensation processes (The evaporation process was done with $(\mathrm{Tw}=300 \mathrm{~K}, \mathrm{Vel}=0.6 \mathrm{~m} / \mathrm{s})$ and the condensation process was done with $(\mathrm{Tw}=290 \mathrm{~K}$, Tin=312K, Vel=0.01 m/s and the first layer $=2 * 10-6 \mathrm{~m})$.

\begin{tabular}{|c|c|c|c|}
\hline \multicolumn{2}{|l|}{ Evaporation Process } & \multicolumn{2}{|l|}{ Condensation Process } \\
\hline $\begin{array}{l}\text { Axial division } x \\
\text { Maximum element } \\
\text { size }\end{array}$ & $\begin{array}{l}\text { H.T Coefficieint at } \\
(\mathrm{Tw}=300 \mathrm{~K}, \mathrm{Vel}=0.6 \\
\mathrm{m} / \mathrm{s})\left(\mathrm{w} / \mathrm{m}^{2} . \mathrm{K}\right)\end{array}$ & $\begin{array}{l}\text { Axial division } \mathrm{x} \\
\text { Maximum element } \\
\text { size }\end{array}$ & $\begin{array}{l}\text { Vapour } \\
\text { fraction at outlet } \\
(\mathrm{Tw}=290 \mathrm{~K}, \\
\text { Tin=312K, Vel=0.01 } \\
\mathrm{m} / \mathrm{s}) \text { first layer }=2 \times 10^{-} \\
{ }^{6} \mathrm{~m}\end{array}$ \\
\hline $101 \times\left(1.7 \times 10^{-4}\right)$ & 935.5 & $101 \times\left(2.6 \times 10^{-4}\right)$ & 0.71 \\
\hline $121 \times\left(1.5 \times 10^{-4}\right)$ & 956 & $121 \times\left(2.4 \times 10^{-4}\right)$ & 0.67 \\
\hline $131 \times\left(1.5 \times 10^{-4}\right)$ & 957.7 & $131 \times\left(2.3 \times 10^{-4}\right)$ & 0.668 \\
\hline $151 \times\left(1.4 \times 10^{-4}\right)$ & 961 & $151 \times\left(2.2 \times 10^{-4}\right)$ & 0.665 \\
\hline
\end{tabular}
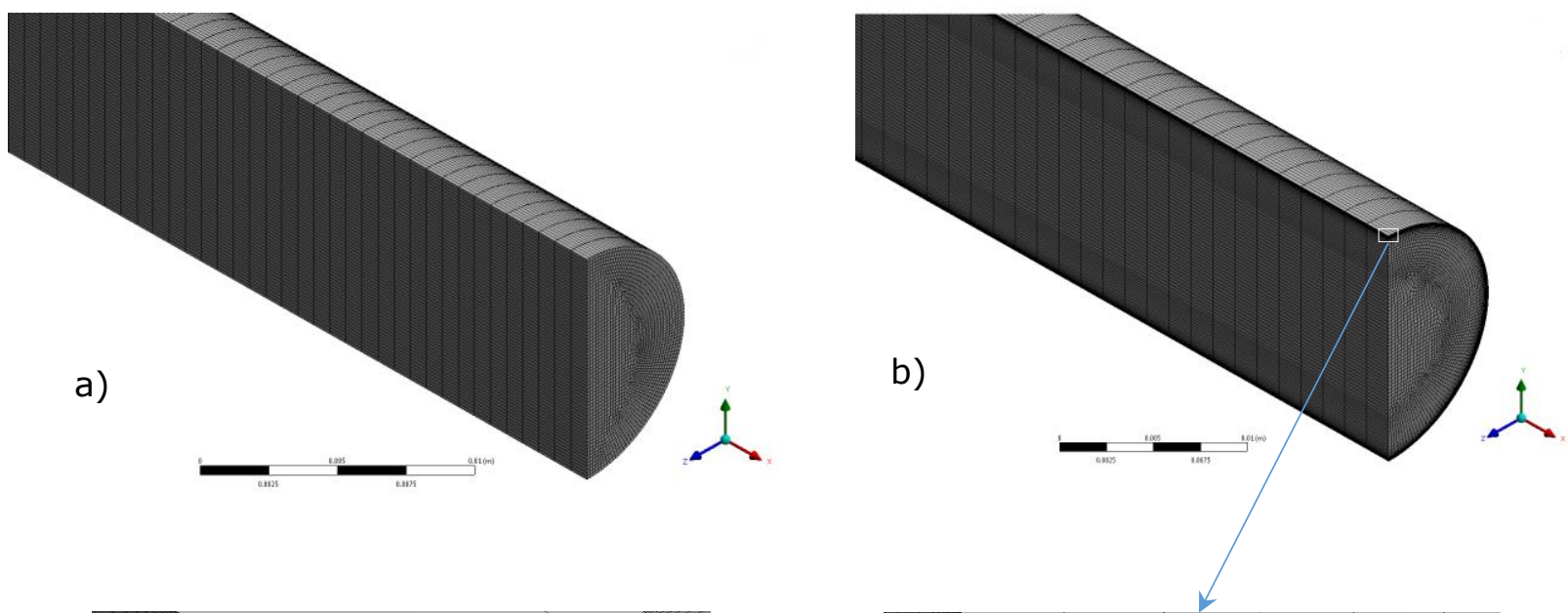

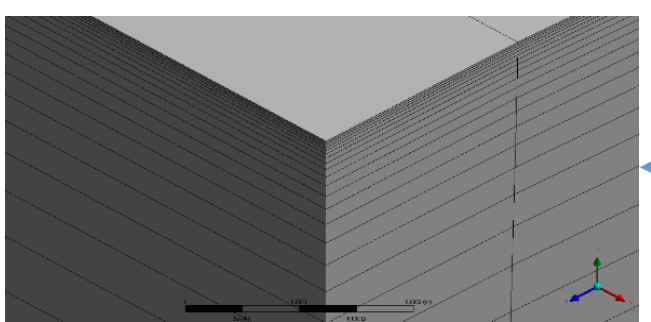

d)

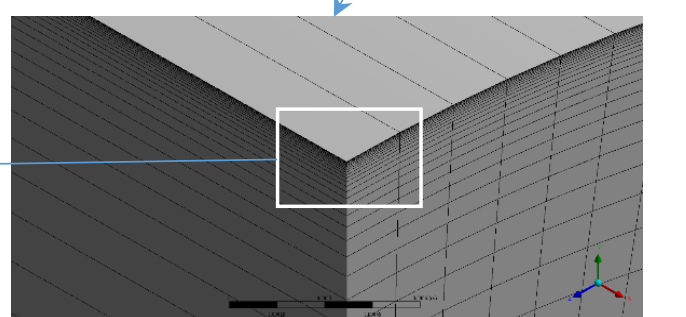

c)

Figure 2. Meshes used in this study a) Evaporation process mesh, b) Condensation process mesh and c) Distance of the layers gradient. 


\section{Calculation model (Evaporation process)}

Evaporation has been modelled as the transient process in different work [20, 25, 28]. The governing equations used for the evaporation process are continuity, momentum, energy, turbulence and volume fraction models, which are presented in Ansys documentation $[38,39]$ as repeated in the following for convenience.

Continuity

$$
\frac{\partial}{\partial t}\left(\rho_{m}\right)+\nabla \cdot\left(\rho_{m} \vec{v}_{m}\right)=0
$$

Momentum

$$
\begin{aligned}
\frac{\partial}{\partial t}\left(\rho_{m} \vec{v}_{m}\right)+\left(\rho_{m} \vec{v}_{m}\right) \cdot \nabla \vec{v}_{m} & \\
& =-\nabla P_{m}+\nabla \cdot\left(\mu_{m} \nabla \vec{v}_{m}\right)+\rho_{m} g+\vec{F}+\nabla \cdot \sum_{k=1}^{n} \varphi_{k} \rho_{k} \vec{v}_{d r, k} \vec{v}_{d r, k}
\end{aligned}
$$

Where $\vec{F}$ is the body force and $\mu_{m}$ mixture viscosity.

$$
\begin{gathered}
\vec{v}_{m}=\frac{\sum_{k=1}^{n} \varphi_{k} \rho_{k} \vec{v}_{k}}{\rho_{m}} \\
\rho_{m}=\sum_{k=1}^{n} \varphi_{k} \rho_{k} \\
\mu_{m}=\sum_{k=1}^{n} \varphi_{k} \mu_{k} \\
\vec{v}_{d r, k}=\vec{v}_{k}-\vec{v}_{m}
\end{gathered}
$$

Energy

$$
\nabla \cdot \sum_{k=1}^{n}\left(\varphi_{k} \vec{v}_{k}\left(\rho_{k} E_{k}+P\right)\right)=\nabla \cdot\left(k_{f} \nabla T\right)+S_{E}
$$

Where

$$
E_{k}=h_{k}-\frac{P}{\rho_{k}}+\frac{v_{k}^{2}}{2}
$$


Two-equation turbulence models allow the resolve of both a turbulent length and time scale by solving two separate transport equations. The standard k- $\varepsilon$ model in Ansys Fluent falls within this class of models and has become the work-horse of practical engineering flow calculations in the time since it was proposed by Launder and Spalding [39]. The standard k- $\varepsilon$ is a model based on transport equations for the turbulence kinetic energy $(\mathrm{k})$ and its dissipation rate $(\varepsilon)$. The model transport equation for $(\mathrm{k})$ is derived from the particular equation, while the model transport equation for $\varepsilon$ was obtained using physical reasoning and bears little resemblance to its mathematically accurate complement. In the derivation of the k- $\varepsilon$ model, a fully turbulent flow is assumed and the effects of molecular viscosity are negligible. The standard $\mathrm{k}-\varepsilon$ model is, therefore, valid only for fully turbulent flows [38].

The turbulence kinetic energy $(\mathrm{k})$ and its rate of dissipation $(\varepsilon)$ are obtained from the following transport equations or the Standard k- $\varepsilon$ model in Fluent-Solver Theory Guide [39].

From the mixture model a multiphase flow was selected with two fluids: liquid and a vapour. In addition to the continuity and momentum equation, the mixture model also contains the relative (slip) velocity, which was defined as the velocity of a secondary phase (q) relative to the velocity of the primary phase (p):

$$
\vec{v}_{q p}=\vec{v}_{q}-\vec{v}_{p}
$$

In order to calculate the phase volume share, the volume fraction expression was used as follows

$$
\frac{\partial}{\partial t}\left(\varphi_{v} \rho_{v}\right)+\nabla \cdot\left(\varphi_{v} \rho_{v} \vec{v}_{m}\right)=-\nabla \cdot\left(\varphi_{v} \rho_{v} \vec{v}_{d r i f v}\right)+m_{l v}
$$

The $m_{l v}$ is an interaction quality transformation source item from liquid to vapour phase.

\section{Condensation process}

The volume of fluid (VOF) model used in the condensation process which solves momentum, energy, turbulence and the volume fraction was solved under the steady state condition $[18,40]$. This method also solves mass, momentum and energy conservation equations for the condensing film.

Momentum

$$
\nabla \cdot(\rho \vec{v} \vec{v})=-\nabla P+\nabla \cdot[\mu \nabla \vec{v}]+\rho g+\vec{F}
$$


Energy

$$
\nabla \cdot(\vec{v}(\rho E+p))=\nabla \cdot\left(K_{e f f} \nabla T\right)+S_{E}
$$

Where $E$ is the energy and can calculate by

$$
E=\frac{\sum_{k=1}^{2} \varphi_{k} \rho_{k} E_{k}}{\sum_{k=1}^{2} \varphi_{k} \rho_{k}}
$$

Where $E_{k}$ for each phase is based on the specific heat of that phase and the shared temperature. The properties $\rho$ and $k_{\text {eff }}$ (effective thermal conductivity) are shared by the phases. The source term, $S_{h}$ contains contributions from radiation, as well as any other volumetric heat sources.

The tracking of the interfaces between the phases is carried out by the solution of a continuity equation for the volume fraction of both phases. For the two phases, this equation has the following form:

$$
\nabla \cdot\left(\varphi_{l} \rho_{l} \vec{v}_{m}\right)=-\nabla \cdot\left(\varphi_{l} \rho_{l} \vec{v}_{\text {drif } l}\right)+S_{M}
$$

In general, the acetone density can be calculated using

$$
\rho=\varphi_{l} \rho_{l}+\left(1-\varphi_{l}\right) \rho_{v}
$$

The transition SST model was used as a viscous model; this model is based on the coupling of the SST $k-\omega$ transport equation with two other transport equations, one for intermittency and one for the transition onset criteria, in terms of momentum-thickness Reynolds number. The transport equation for the intermittency $\gamma$ is defined as:

$$
\frac{\partial\left(\rho U_{j} y\right)}{\partial x}=P_{y 1}-E_{y 1}+P_{y 2}-E_{y 2}+\frac{\partial}{\partial x_{j}}\left[\left(\mu+\frac{\mu_{t}}{\sigma_{y}}\right) \frac{\partial y}{\partial x_{j}}\right]
$$

Where $y$ is the wall distance, $P_{y 1}$ and $E_{y 1}$ are transition sources and $P_{y 2}$ and $E_{y 2}$ are destruction source; they are defined as:

$$
\begin{gathered}
P_{y 1}=2 F_{\text {length }} \rho S \sqrt{y F_{\text {onset }}} \\
E_{y 1}=P_{y 1} y \\
P_{y 2}=0.06 \rho y \Omega F_{\text {turb }}
\end{gathered}
$$




$$
E_{y 2}=50 P_{y 2} y
$$

Where $\mathrm{S}$ is the strain rate magnitude, $F_{\text {length }}$ is an empirical correlation which controls the length of the transient region and $\Omega$ is the vorticity magnitude.

The condensation process, used an Eulerian modelling wall film, solved mass, momentum and energy conservation equations. Conservation of mass for two dimensional film in three dimensional domain is

$$
\frac{m_{s}}{\rho_{l}}=\nabla_{s} \cdot\left[h \vec{V}_{l}\right]
$$

Where $m_{S}$ is a mass source per unit area due to droplet collection and phase change, $\nabla_{S}$ is the surface gradient operator, $h$ is the film height $\vec{V}_{l}$ the mean film velocity.

The film momentum conservation is given by

$$
\nabla_{s} \cdot\left(h \vec{V}_{l} \vec{V}_{l}\right)=\frac{h \nabla_{s} P_{L}}{\rho_{l}}+\left(\vec{g}_{\tau}\right) h+\frac{3}{2 \rho_{l}} \vec{\tau} f s-\frac{3 v_{l}}{h} \vec{V}_{l}+\frac{q}{\rho_{l}}
$$

Where

$$
P_{L}=P_{v}-\rho h(\vec{n} \cdot \vec{g})-\sigma \nabla_{s} \cdot\left(\nabla_{s} h\right) \quad 23
$$

The term on the left-hand side is a convective effect. On the right-hand side, the first term is the effect of the vapour pressure, the second term is gravity in a direction parallel to the film, the third term is a viscous shear force at the vapour film interface, the fourth term is viscous force on the film and the last term represents droplet collection. The conservation of film energy is given as

$$
\nabla_{s} \cdot\left(h \vec{V}_{f} T_{f}\right)=\frac{1}{\rho c_{p}}\left\{2 k_{f}\left[\frac{T_{s}-T_{w}}{h}-\frac{2 T_{f}}{h}\right]+q_{i m p}+m_{v} L\left(T_{s}\right)\right\}
$$

Where

$T_{S}$ is the temperature at the film-vapour interface;

$T_{f}$ is the average film temperature;

$T_{w}$ is the wall temperature;

$q_{\text {imp }}$ is the source term due to liquid impingement from the bulk flow to the wall;

$m_{v}$ is the mass vaporization or condensation rate and

$L$ is the latent heat associated with the phase change. 
It is clear that if a piece-wise linear profile has been assumed: the film temperature varies from $T_{w}$ to $T_{f}$ in the lower half of the film and from $T_{f}$ to $T_{s}$ in the upper half

A UDF code for mass transfer rate and the energy source which (shown in table 2) developed by Lee [36] in 1979 written in the C language, this code has been successfully applied by other researchers $[19,20,25]$ for the boiling, evaporation and condensation's applications. The UDF file is linked with Fluent to calculate the source concentration of each phase.

Table 2. Construction of the user-developed subroutine.

\begin{tabular}{|c|c|c|}
\hline Liquid phase & & \\
\hline Evaporation & $S_{M}=-\epsilon \varphi_{l} \rho_{l}\left|\frac{T_{l}-T_{\text {sat }}}{T_{\text {sat }}}\right|$ & 25 \\
\hline Condensation & $S_{M}=\epsilon \varphi_{v} \rho_{v}\left|\frac{T_{v}-T_{\text {sat }}}{T_{\text {sat }}}\right|$ & 26 \\
\hline \multicolumn{3}{|l|}{ Vapour phase } \\
\hline Evaporation & $S_{M}=\epsilon \varphi_{l} \rho_{l}\left|\frac{T_{l}-T_{\text {sat }}}{T_{\text {sat }}}\right|$ & 27 \\
\hline Condensation & $S_{M}=-\epsilon \varphi_{v} \rho_{v}\left|\frac{T_{v}-T_{s a t}}{T_{\text {sat }}}\right|$ & 28 \\
\hline \multicolumn{3}{|l|}{ Energy } \\
\hline Evaporation & $S_{E}=-\epsilon \varphi_{l} \rho_{l}\left|\frac{T_{l}-T_{\text {sat }}}{T_{\text {sat }}}\right| \Delta H$ & 29 \\
\hline Condensation & $S_{E}=\epsilon \varphi_{v} \rho_{v}\left|\frac{T_{v}-T_{\text {sat }}}{T_{\text {sat }}}\right| \Delta H$ & 30 \\
\hline
\end{tabular}

Where $S_{M}$ is the source term in mass conservation equation $\left(\mathrm{kg} / \mathrm{m}^{3} \mathrm{~s}\right)$, SE source term in the energy equation $\left(\mathrm{J} / \mathrm{m}^{3} \mathrm{~s}\right), \epsilon$ is a time relaxation factor with unit $\mathrm{s}^{-1}$, which is set equal to $0.1 \mathrm{~s}^{-1}$ (to keep the interface temperature close to the saturation temperature) in both of evaporation and condensation cases, and $\varphi_{l}$ and $\varphi_{v}$ are the volume fraction of the liquid and vapour respectively.

\section{Validation and Numerical result}

To validate the numerical work for the both processes (condensation \& evaporation), two previous studies for each process were repeated with the same geometry and same boundary condition. Experimental study of falling film evaporation heat transfer of Yang and Shen [34] are replicated using the model and the numerical method of this work by ANSYS® Fluent. The previous work studied falling film heat transfer for horizontal tubes in order to show how the heat transfer coefficient is affected by different parameters such as flow density evaporation temperatures, temperature difference between wall and saturation water. The geometry of the previous work is a tube with ID $=12 \mathrm{~mm}$ and 
length $=500 \mathrm{~mm}$. Heat flux is provided by the heater $10 \mathrm{~mm}$ in diameter embedded inside of the tube. The researchers stated that the experiment results followed by a $\pm 15 \%$, relative error. The results of the heat transfer coefficient as a function to the supplied heat flux at $0.022(\mathrm{~kg} / \mathrm{ms})$ density flow shows a good agreement with the numerical repeated work as shown in Figure 3a. To be more certain about the validation results of the evaporation process, another work of Gao et al. [25] who studied numerically the boiling heat transfer in horizontal tube was repeated. The results which are in the relationship between the heat transfer coefficient and the velocity at different temperature show a good agreement (maximum difference is $4 \%$ in the case of temperature $=351 \mathrm{~K}$ and velocity $=2 \mathrm{~m} / \mathrm{s}$ ), as shown in Figure $3 b$.
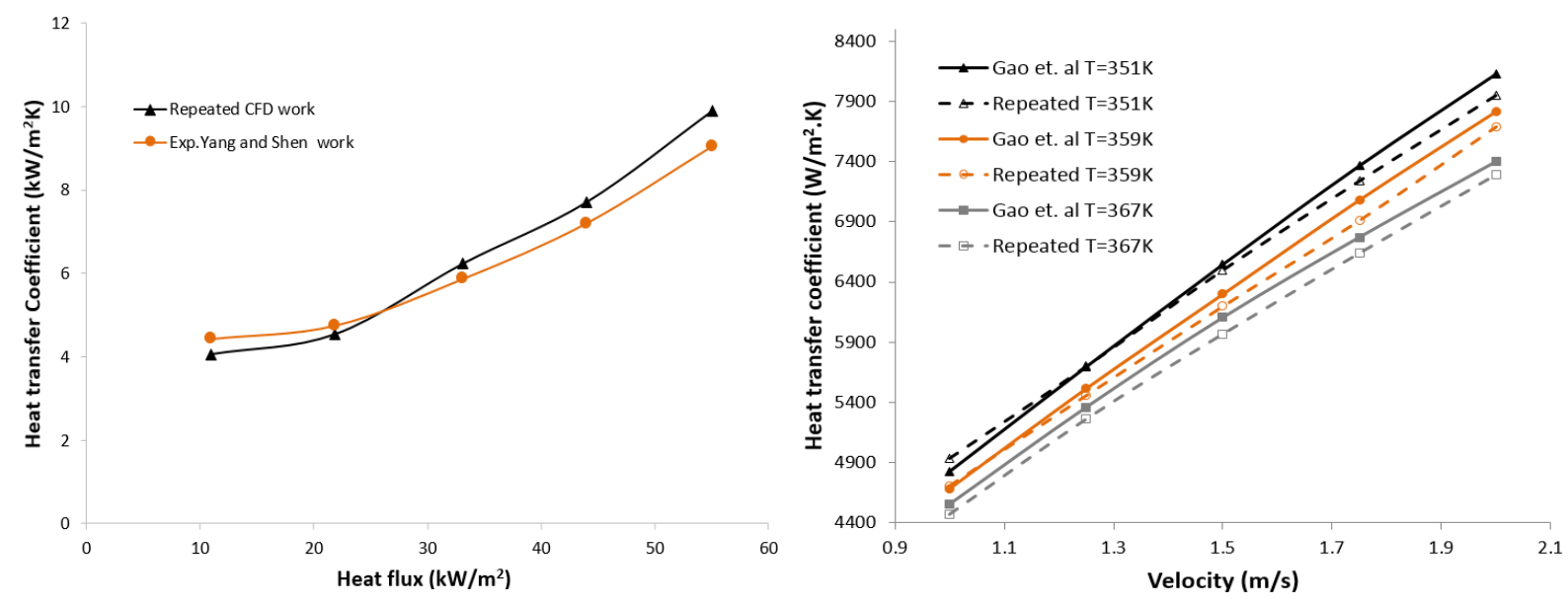

Figure 3. validation of the evaporation process a) comparison of the results of the relationship between heat transfer coefficient and supplied heat flux for the current work and Yang and Shen [34]'s work. b) comparing the results of the relationship between heat transfer coefficient and velocity of the present work and Gao. et al. [25]'s work.

For the condensation process another experimental of Shao and Granryd [41] work was repeated. This experiment have been conducted with both pure R32, R134a and their mixtures inside a tube (10 m long, $6 \mathrm{~mm}$ ID), with a mass flux of $131-369 \mathrm{~kg} / \mathrm{m}^{2} \mathrm{~s}$ and average condensation temperature of $23-40^{\circ} \mathrm{C}$. The heat balance error from the inlet to exit of the condenser is in most cases less than $\pm 2 \%$. The researchers stated that the analysis of error propagation demonstrates that the total uncertainty in heat transfer coefficient is mostly $10-15 \%$. The results of the heat transfer coefficient related to the liquid mass fraction shows a good agreement between the experimental work and the repeated CFD modelling. Again, to be more certain about the validation results of the condensation process another numerical study of Padoin and Soares [19] was repeated. They modelled the steam condensation in a pipe. The validation of this work performed using a refined mesh. The results of the vapour quality (vapour volume fraction) along the pipe for three different boundary conditions show also good agreement, the maximum difference between the [19] and repeated work is $14 \%$ at the outlet section at (Diameter $=0.05 \mathrm{~m}$, Velocity $=4 \mathrm{~m} / \mathrm{s}$ and Temperature $=293.15 \mathrm{~K}$ ) as shown in Figure 4. 

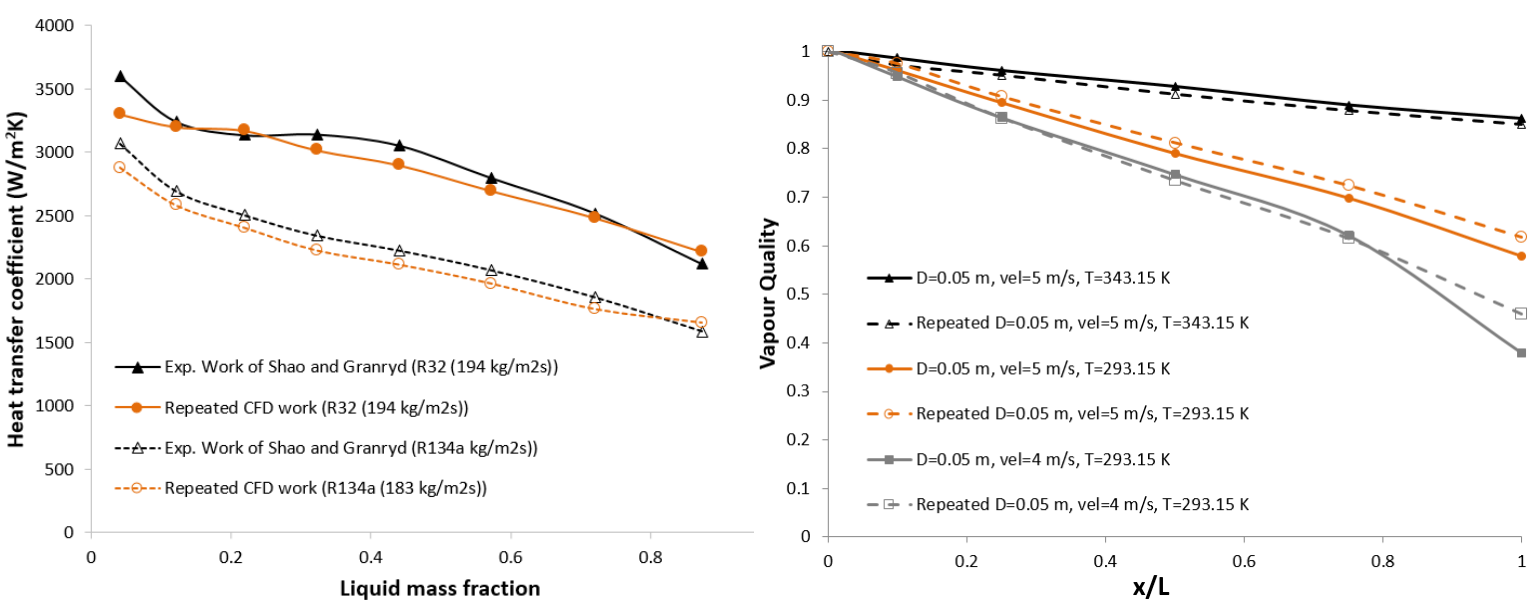

Figure 4. Validation of the condensation process a) comparison between the heat transfer coefficient as a function to the liquid mass fraction for Shao and Granryd [41] experimental work and present work. b) Comparing the results of the vapour quality along the tube for condensation process of the present work and Padoin and Soares [19] work.

\section{Evaporation process results}

The results of the simulation of the acetone evaporation process in the horizontal tube are collected for two different wall temperatures (298 and 300K) and different velocities $(0.005,0.01,0.02$, 0.04 and $0.06 \mathrm{~m} / \mathrm{s}$ ) in an overall evaporation simulation time of $20 \mathrm{~s}$. These conditions reflect similar conditions to those for the evaporator in the VARS.

Figure 5 illustrates the relationship between the heat transfer coefficient and the velocity at the upper side (upper half of the tube), lower side (lower half of the tube) and the average velocity at different temperature cases. The importance of investigating the effect of velocity on the heat transfer coefficient behaviour is to give a better understanding of the vapour generation flow rate and absorbing heat from the surrounding, which effect on the performance of the VARS. From Figure 5, it can be seen that when the temperature of the wall increases by only $2{ }^{\circ} \mathrm{C}$, the vapour generation and acceleration of the evaporation increase too. By generating more vapour, the overall heat transfer coefficient in the evaporator tube decreases because the convection heat transfer coefficient of the vapour is very small compared with the liquid and this behaviour is very clear if the heat transfer coefficient on the upper and lower surfaces are compared. The heat transfer coefficient at the lower side of the tube is much higher than the upper side, because the lower side is the place of the saturated liquid which has a higher heat transfer coefficient; however, the upper side is a place where the vapour collected with a low heat transfer coefficient due to the lower density and conductivity of the vapour in comparison to liquid. Figure 5 also shows the heat transfer coefficient increases with the velocity, and that for the lower side, the rate of increase is highest, between 0.005 and $0.02 \mathrm{~m} / \mathrm{s}$, then it reaches a maximum because by increasing the velocity, more vapour mixes with the liquid phase which leads to the vapour influence reducing the heat transfer coefficient on the lower side of the wall. 


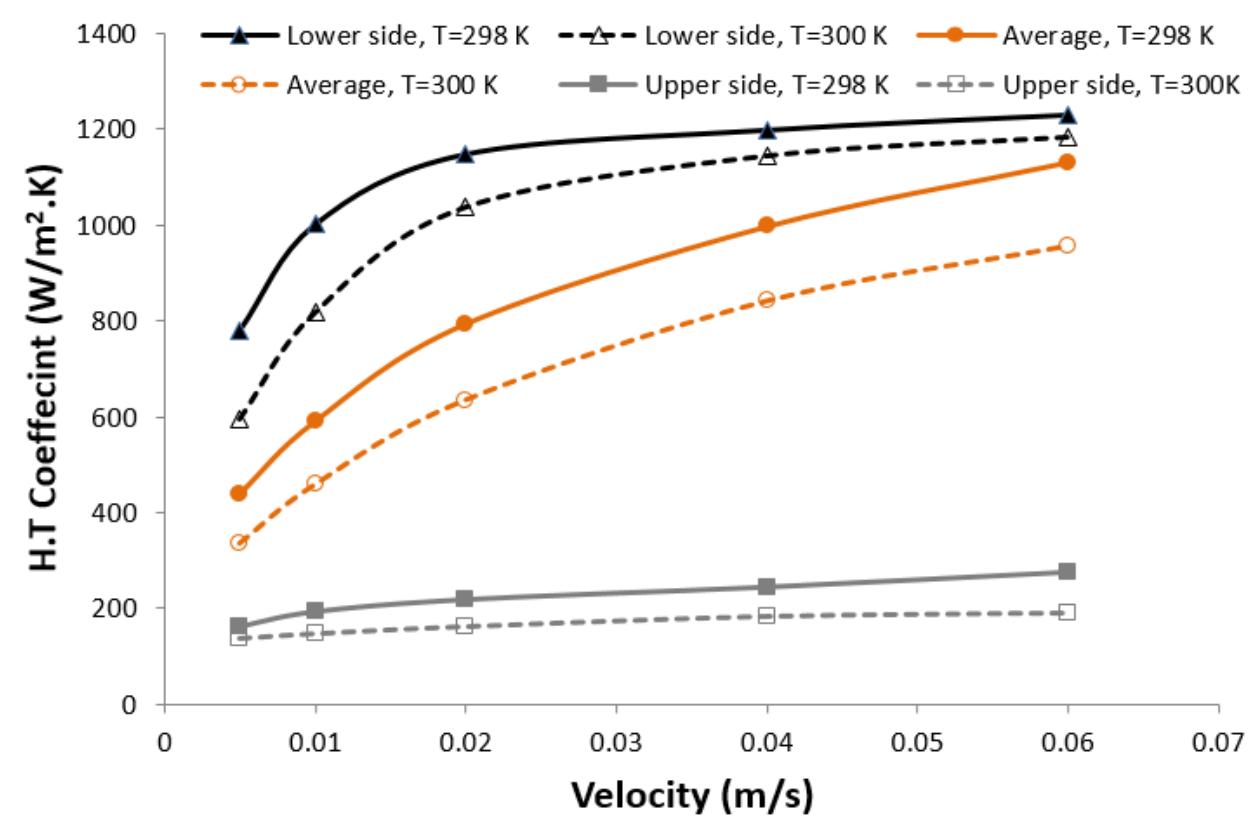

Figure 5. The relationship between the heat transfer coefficient and the velocity of the fluid at the upside, downside and the average in the evaporation case. $T_{w}=298 \& 300 \mathrm{~K} . \mathrm{P}=0.22$ bar. $\mathrm{T}_{\text {sat }}=296 \mathrm{~K}$.

Figure 6 shows the vapour generation behaviour over the $20 \mathrm{~s}$ (enough time to reach stable vapour generation level) simulation. It is clear that the generation of the vapour volumetric content increases as the wall temperature increases and as velocity decreases because the fluid has adequate time to get more heat and evaporate. With $0.005 \mathrm{~m} / \mathrm{s}$ velocity, the evaporation rate increases sharply in the first 5 second, then the amount of this increase drops because the tube going to be full with the vapour and there is an amount of the vapour exits from the tube, consequently, the generated vapour is approximately equal to the exit vapour.

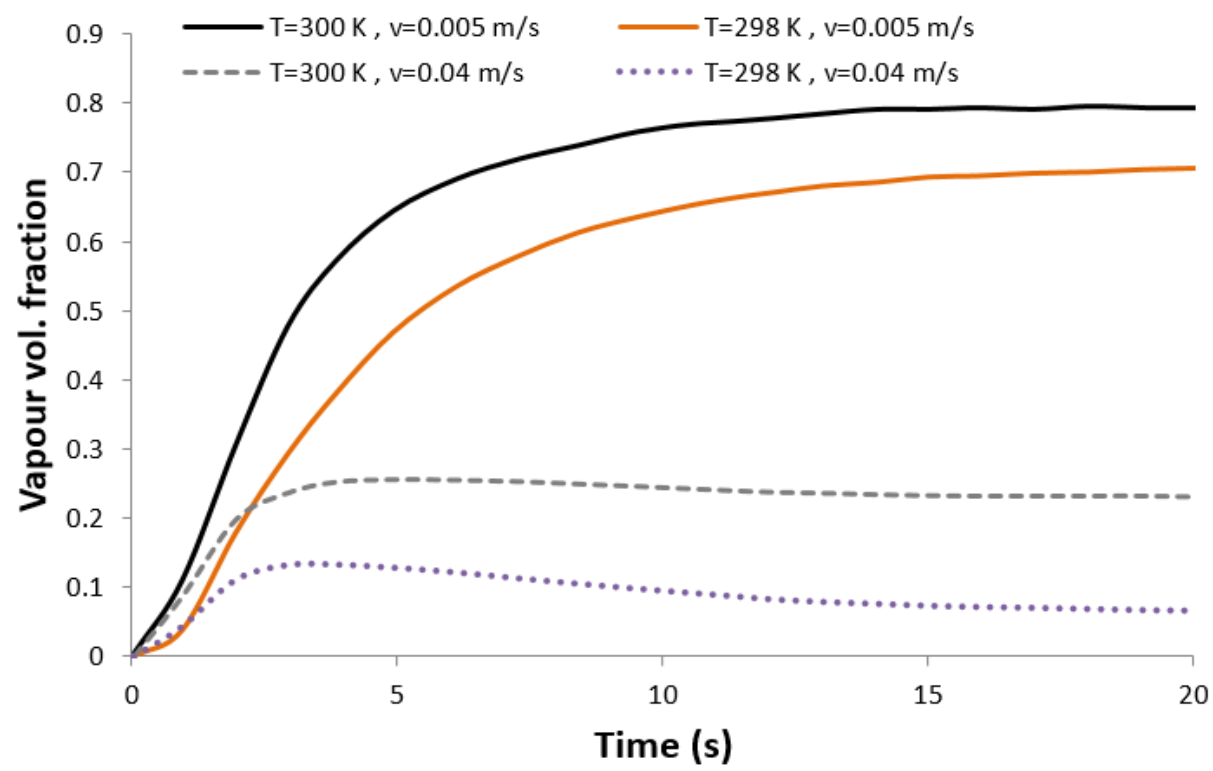

Figure 6. Relationship of vapour vol. fraction in the evaporator with the time at different velocity $(0.005 \& 0.04 \mathrm{~m} / \mathrm{s})$ and different temperatures $(298 \& 300 \mathrm{~K})$. 
Figure 7 shows the variation of mass transfer in $\mathrm{kg} / \mathrm{m}^{3} . \mathrm{s}$ and the vapour volume fraction with inlet velocity of the liquid acetone. Figure 7a shows that the mean volumetric evaporation rate for the entire tube decreases with increasing velocity for both temperature conditions ( $298 \& 300 \mathrm{~K}$ ). Figure $7 \mathrm{~b}$ shows that the volume fraction of the vapour decreases exponentially with increasing velocity of the liquid acetone because by increasing the mass flux, which increases with the velocity, the fluid has decreased energy absorption per unit mass. The mass transfer and the vapour generation rate increase with wall temperature as expected.
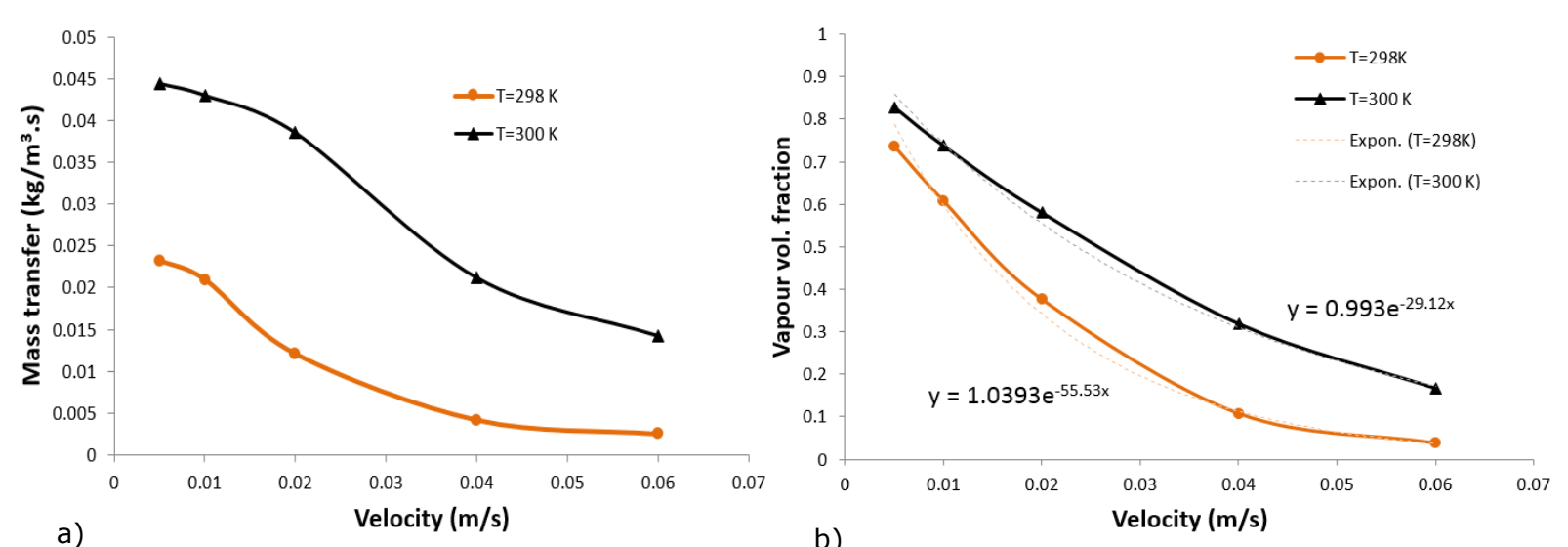

Figure 7. Relationship of a) mass transfer and b) vapour volume fraction, with the velocity of the fluid at temperatures 298 and $300 \mathrm{~K}$ at the end of the evaporator.

Figure 8 presents contours of the vapour phase (right hand side of the tube) and the temperature (left hand side of the tube) distribution at $(0.005$ and $0.04 \mathrm{~m} / \mathrm{s})$, temperature $(298 \& 300 \mathrm{~K})$ at the outlet cross section at $20 \mathrm{~s}$. Figure $8 \mathrm{a}$ shows a pure acetone vapour appears at the upside of the tube in a 0.005 $\mathrm{m} / \mathrm{s}$ velocity case with vapour quality (volume fraction) 0.7 on the downside. By decreasing the temperature to $298 \mathrm{~K}$ (Figure $8 \mathrm{~b}$ ), the vapour quality varies between 0.9 at the upper half cross section of the tube and 0.5 at the lower half. By increasing the velocity with the higher temperature $(300 \mathrm{~K})$, the vapour quality decreases and a pure acetone spot appear in the outlet section with the small area. Increasing the velocity to $0.04 \mathrm{~m} / \mathrm{s}$ with temperature equal to $298 \mathrm{~K}$ as shown in figure $8 \mathrm{~d}$, which shows the vapour quality drops to 0.8 at the top side with just a smaller area and more than half of the out section is pure acetone liquid (pool of liquid). The mixture model of the numerical solution causes the gradient colour because this model not suitable for immiscible phases. The red and the blue colours represent the pure vapour and liquid phases respectively, whereas, the other gradient colours represent a mixture of both phases.

The left hand sides of the tube for Figures $8 \mathrm{a}, \mathrm{b}, \mathrm{c}$ and $\mathrm{d}$ at show the temperature reduces towards the central part of the section, but the details of the temperature distribution change from one case to another. With slower velocity in the evaporator, the temperature at the out section is warmer than the higher velocity because the fluid in the tube has more time to gain heat from the wall. The figures also show that the gravity and the phase's density distribution have an influence on the 
temperature distribution. Whereas, the lower side of the tube, which has more liquid phase has lower temperature; this gives the non-circular shape to temperature distribution at the cross section of the tube.

Figure 9 shows how the phase distribution changes for a different velocities of the flow at $T_{w}$ equal $300 \mathrm{~K}$. At low velocity $(0.005 \mathrm{~m} / \mathrm{s})$ as shown in Figure 9a, the flow enters as though through a porous plug at entry and the initial progression shows that liquid falling to the bottom of the tube under gravity and being rapidly evaporated. The picture changes with increasing velocity. Figure 9e shows, when the velocity is $0.06 \mathrm{~m} / \mathrm{s}$ the system cannot evaporate a high quantity of the fluid and a small quantity of low quality vapour (concentration of the vapour is low) appears at the top of the tube with a pool of liquid at the bottom which decreases along the axial coordinate of the tube.

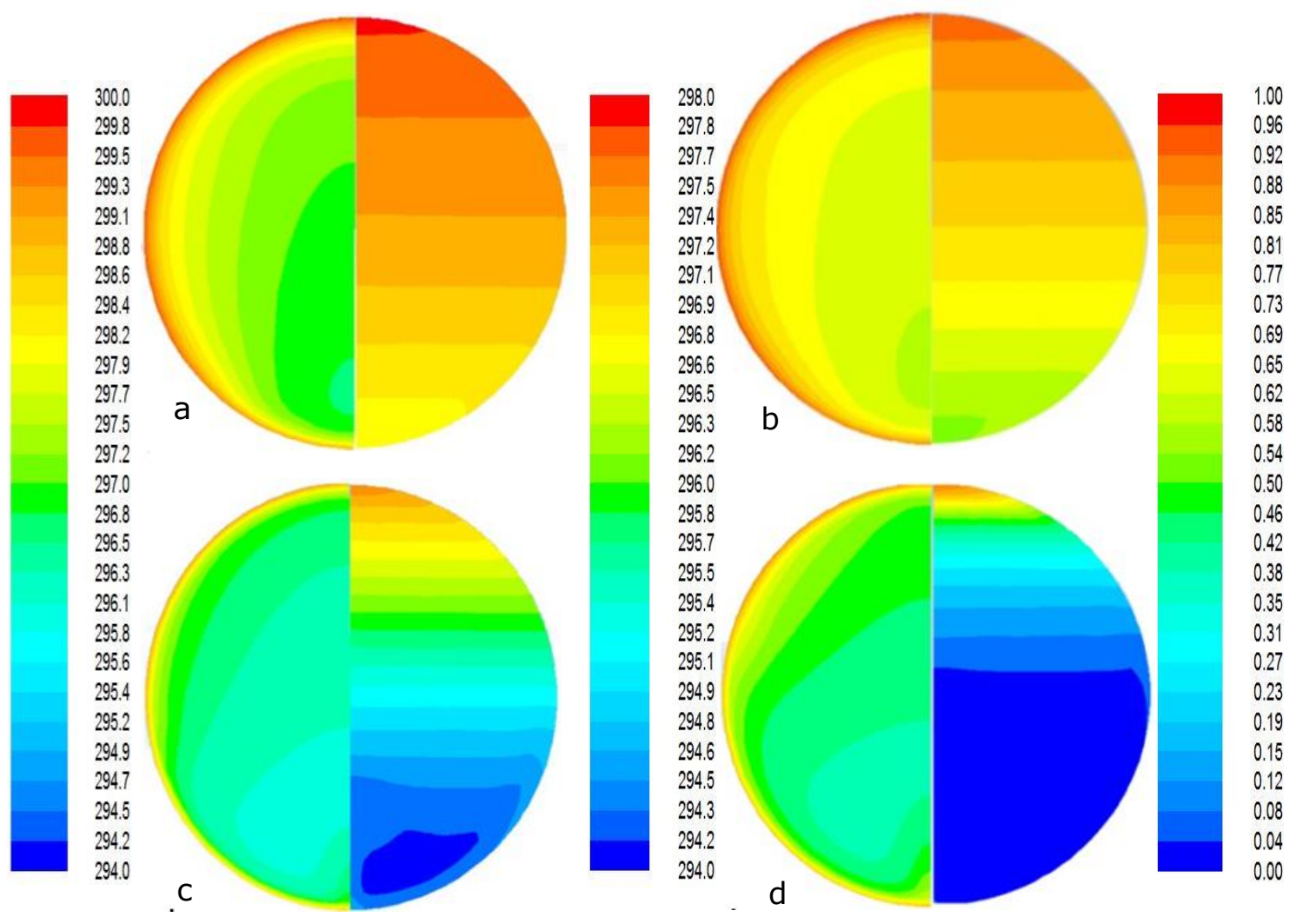

Figure 8. Contours of the phase (right hand side) and temperature (left hand side) distributions for a$V_{\text {in }}=0.005 \mathrm{~m} / \mathrm{s}, T_{\mathrm{w}}=300 \mathrm{~K}, \mathrm{~b}-\mathrm{Vin}=0.005 \mathrm{~m} / \mathrm{s}, T_{\mathrm{w}}=298 \mathrm{~K}, \mathrm{c}-\mathrm{V}_{\text {in }}=0.04 \mathrm{~m} / \mathrm{s}, T_{\mathrm{w}}=300 \mathrm{~K}$ and d- $V_{\text {in }}$ $=0.04 \mathrm{~m} / \mathrm{s}, \mathrm{T}_{\mathrm{w}}=298 \mathrm{~K}$, (Evaporation case). 

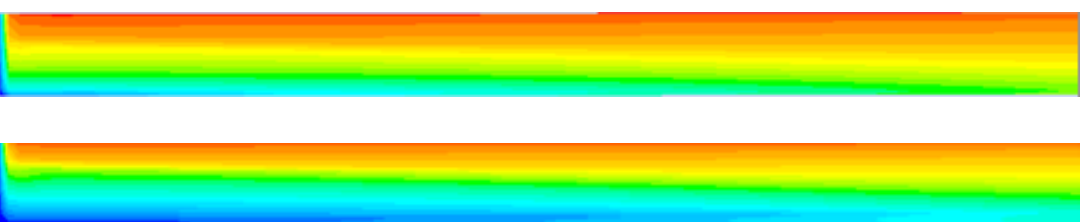

Figure 9. Contours of the phase distributions at the symmetric section, $T_{w}=300 \mathrm{~K}$ for different velocities a- $0.005 \mathrm{~m} / \mathrm{s}$, b- $0.01 \mathrm{~m} / \mathrm{s}, \mathrm{c}-0.02 \mathrm{~m} / \mathrm{s}, \mathrm{d}-0.04 \mathrm{~m} / \mathrm{s} \&$ e- $0.06 \mathrm{~m} / \mathrm{s}$ (Evaporation case).

\section{Condensation process results}

The acetone condensation process results are collected for two different wall temperatures (294 and $290 \mathrm{~K})$ with different velocities $(0.01,0.03,0.05,0.08$ and $0.1 \mathrm{~m} / \mathrm{s})$ under the steady state condition. These conditions were chosen as they reflect those of the condenser in the VARS.

Understanding the condensation process of acetone vapour under these condition is important to increases the rate of the condensation and improve the performance of VARS. Figure 10 shows how the mass transfer in $\mathrm{kg} / \mathrm{m}^{3} \mathrm{~s}$ changes with the velocity of the flow inside the condenser knowing that the surface area of the condenser is $0.0189 \mathrm{~m}^{2}$. Increasing the velocity in the tube decreases the mass transfer or the phase change at the same wall temperature; for example, the mass transfer drops from $0.0005 \mathrm{~kg} / \mathrm{m}^{3} \mathrm{~s}$ at $0.005 \mathrm{~m} / \mathrm{s}$ to $0.00024 \mathrm{~kg} / \mathrm{m}^{3} \mathrm{~s}$ at $0.1 \mathrm{~m} / \mathrm{s}$ in the case of the wall temperature at $294 \mathrm{~K}$ and the inlet temperature at $311 \mathrm{~K}$. Figure 10 also shows that with decreasing wall temperature, the mass rate increases, because there is a bigger temperature difference between $T_{\text {sat }}$ and $T_{w}$. Figure 11 illustrates the condensed liquid volume fraction at the outlet cross section changing with the velocity for the different temperatures. It shows that the liquid phase volume fraction drops dramatically with increasing the velocity from 0.005 to $0.05 \mathrm{~m} / \mathrm{s}$. Decreasing in the wall temperature leas to increase the volume fraction and at velocity $0.1 \mathrm{~m} / \mathrm{s}$ the liquid phase does not change significantly by changing the wall and the inlet temperature over the range observed. 


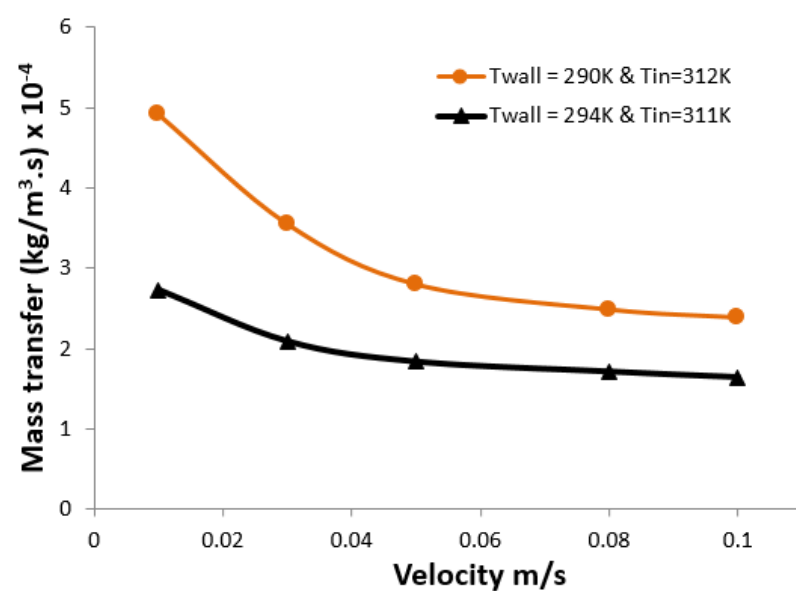

Figure 11. The relationship between the mass transfer with the velocity at two different cases.

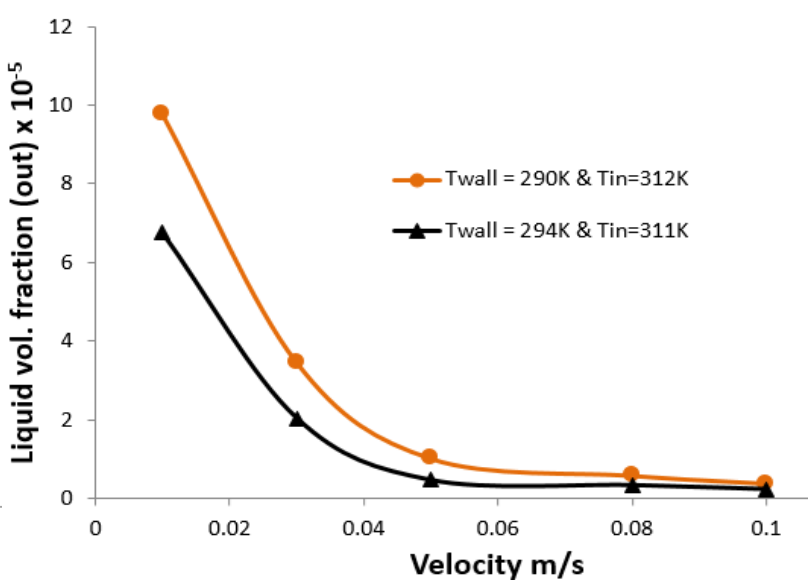

Figure 10. The relationship between the liquid volume fractions with the velocity at two different cases.

Figure 12 shows the variation of the mass transfer at the bottom side along the tube. It is clear that the mass transfer rate rises from zero till the stability level depending on the velocity. For the lower velocity, the mass transfer rate starts at the inlet of the tube and increases dramatically till 0.0024 $\mathrm{kg} / \mathrm{m}^{3} . \mathrm{s}$, then it reaches to the stable level till the end of the tube. For the higher velocity $(0.1 \mathrm{~m} / \mathrm{s})$ the mass transfers after $1 \mathrm{~cm}$ from the inlet which is the minimum distance for the acetone vapour to reject sufficient heat in order to start to change phase; then mass transfer rate increases sharply till reaching the stable level at 0.00095 .

Figure 13 shows that the centreline temperature drops along the tube. When the inlet temperature is $311 \mathrm{~K}$; the outlet temperature depends on the velocity of the flow. For example, they are $297.27 \mathrm{~K}$ at velocity $1 \mathrm{~m} / \mathrm{s}$ and $295.63 \mathrm{~K}$ at a velocity equal to $0.1 \mathrm{~m} / \mathrm{s}$ which means that the temperature drops more with decreasing the velocity of the flow.

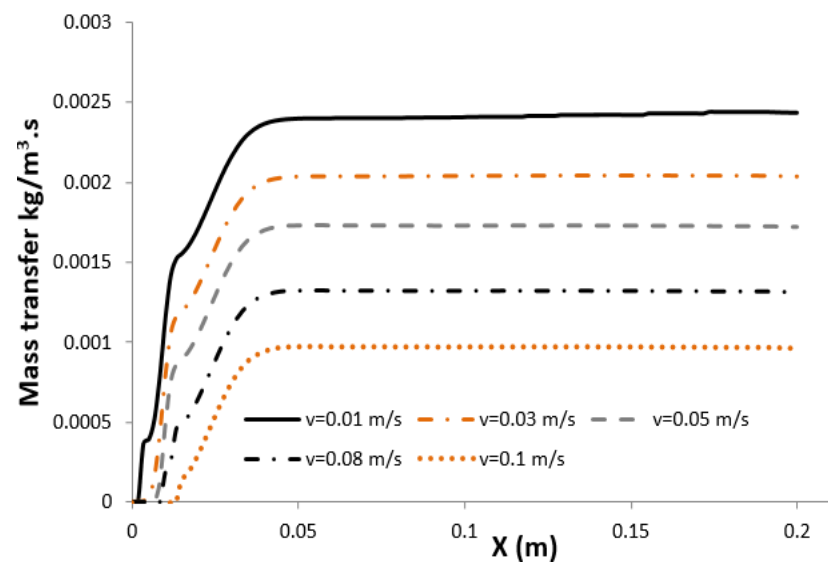

Figure 13. Effect of the velocity on the mass transfer rate along the condenser tube.

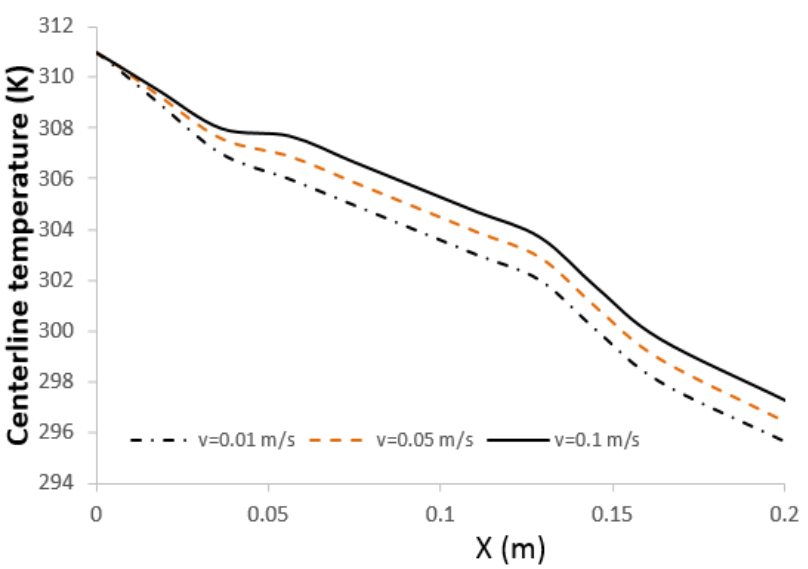

Figure 12. Effect of the velocity on the centreline temperature along the condenser tube. 
Figure 14 shows the variation of the vapour volume fraction of the acetone throughout the tube. The vapour volume fraction illustrated a linear decay profile along the axial coordinate of the tube. A higher decay of the vapour quality, consequently indicates more liquid condensation observed as vapour moves increasingly slowly along the length. For example the vapour quality drops to 0.65 at the end of the tube with inlet velocity equal $0.01 \mathrm{~m} / \mathrm{s}$ but by increasing the velocity till $0.1 \mathrm{~m} / \mathrm{s}$ the vapour quality become 0.85 .

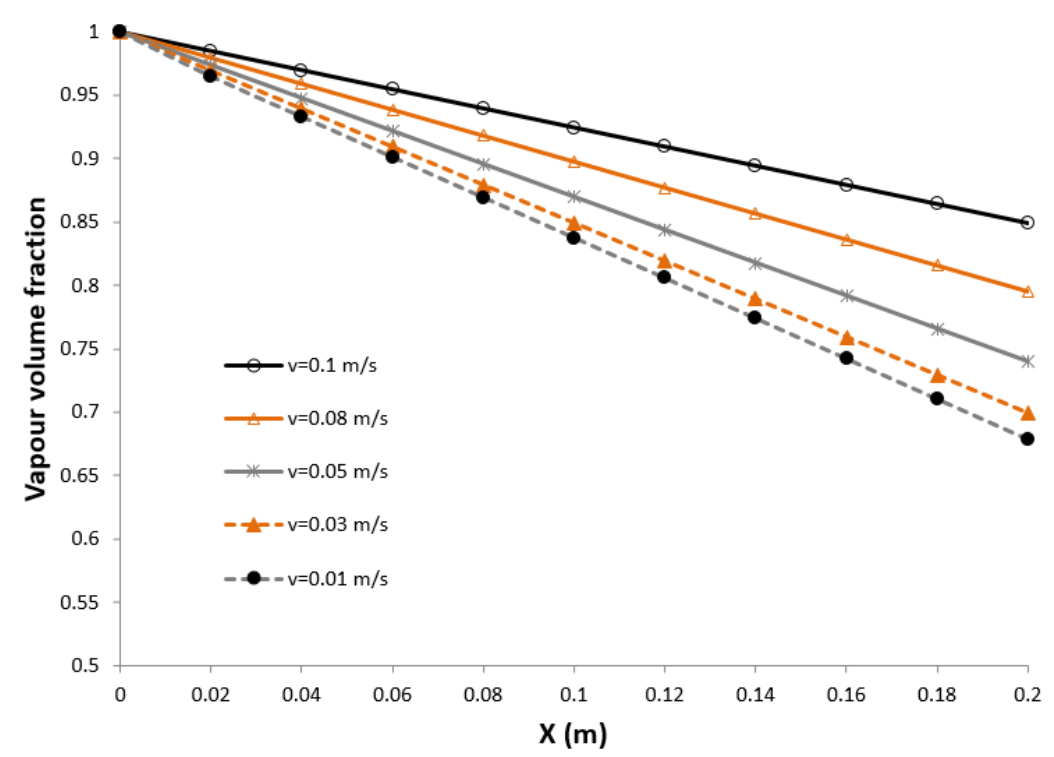

Figure 14. Vapour volume fraction as a function of the axial length of the tube at different velocities.

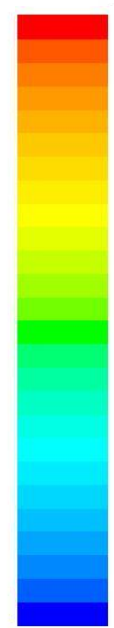

1.00
0.96
0.92
0.88
0.85
0.81
0.77
0.73
0.69
0.65
0.62
0.58
0.54
0.50
0.46
0.42
0.38
0.35
0.31
0.27
0.23
0.19
0.15
0.12
0.08
0.04
0.00
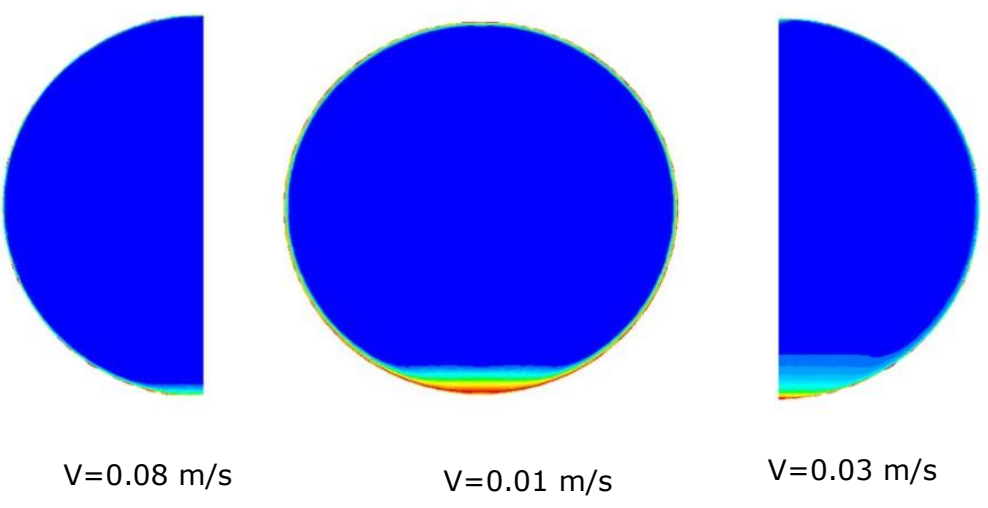

$\mathrm{V}=0.01 \mathrm{~m} / \mathrm{s}$

$\mathrm{V}=0.03 \mathrm{~m} / \mathrm{s}$

Figure 15. Contours of the liquid volume fraction at the outlet cross section of the tube at $\mathrm{Tw}=294 \mathrm{~K}$ with different velocities $(0.01,0.03$ and $0.08 \mathrm{~m} / \mathrm{s})$. 
Figure 15 presents the contours of the liquid volume fraction at the end cross section of the domain at different velocities. It is recognized that the CFD simulations found the thin liquid film formed at the entire inner circumferential surface of the condenser in addition to the collected liquid film at the bottom of the tube due to the effect of gravity on the flow, leading to increasing liquid stream with length. The thickness of the liquid decreases with increasing velocity of the flow. For example when the velocity is $0.01 \mathrm{~m} / \mathrm{s}$ the condensed liquid appears on the wall and the liquid phase quality for the collected acetone at the bottom equals to 1 (pure liquid). The layers above the liquid layer are misty flow and by getting away from the wall, the wetness or the vapour quality decreases. Increasing the velocity decreases the thickness of the liquid phase which collected at the bottom side and decreases the quality of the liquid phase. For example, when the velocity is $0.08 \mathrm{~m} / \mathrm{s}$, no liquid phase is observed at the bottom just a misty flow with a liquid quality 0.35 .

The velocity of the flow and temperature difference between the inlet and the wall have a significant influence on the evaporation and condensation process, this behaviour proved by [22]. The slow velocity (low mass flux) of acetone makes the flow gain or release more heat, consequently better opportunity to reach the saturation temperature and achieving the phase change. A high temperature difference between the inlet flow and the wall with a condition of rapprochement between the inlet and the saturation temperature leads to exchange more heat and reaching to the phase change point.

\section{Conclusion}

Acetone evaporation and condensation processes in the horizontal tube have been simulated numerically using a commercial code ANSYS ${ }^{\circledR}$ (Fluent). These processes are a part of the vapour absorption refrigeration mechanism work. The simulations were conducted with $28000 \mathrm{~Pa}$ for condensation and $22000 \mathrm{~Pa}$ for evaporation with corresponding saturation temperature point of 310 and $296 \mathrm{~K}$ respectively; these conditions reflect the exchange of heat with ambient heat exchangers. It was found that the heat transfer coefficient for both evaporation and condensation processes increases with increasing velocity of the flow and the heat transfer coefficient at the lower side of the tube is much higher than the upper side which fill with the vapour. The heat transfer coefficient increases with increasing the difference of the temperature between the flow and the wall, also, the phase change rate increases as the velocity decreases and the wall temperature increases (evaporation case) or decreases (condensation case). For the condensation case, the vapour quality decreases as the length of the axial tube increase because there is more condensation by increasing the tube length. On the other hand, in the evaporation process, the liquid quality drops with the length of the tube. Consequently, the vapour volume fraction in the condensation and evaporation processes, decrease and increase respectively, with increasing the length of the tube.

Both of the velocity of the flow and the wall and inlet temperatures have a significant influence on the heat transfer coefficient and the phase change process. In the vapour absorption refrigeration 
process the velocity of the flow in both evaporator and condenser should be as slow as possible. A high difference between the inlet and the wall temperature gives better results for both process in condition of the inlet temperature should be near to the saturation temperature. Furthermore, it can concluded that the CFD modelling with ANSYS® Fluent is suitable to simulate these processes, but they need to develop an especial user define function for the source phase change.

\section{Acknowledgement}

This work was funded by The Higher Committee for Education Development (HCED), Iraq, by sponsorship reference D-12-1257 through the PhD Fellowship of the first author.

\section{References}

1. Ajib, S. and A. Karno, Thermo physical properties of acetone-zinc bromide for using in a low temperature driven absorption refrigeration machine. Heat and Mass Transfer, 2008. 45(1): p. 61-70.

2. Joel A W Hamilton, Investigation into discontinuous low temperature waste heat utilisation from a renewable power plant in rural India for absorption refrigeration. 2016, The University of Nottingham.

3. Karno, A. and S. Ajib, Thermodynamic analysis of an absorption refrigeration machine with new working fluid for solar applications. Heat and Mass Transfer, 2008. 45(1): p. 71-81.

4. Mohammed, H.I., D. Giddings, and G.S. Walker, CFD simulation of a concentrated salt nanofluid flow boiling in a rectangular tube. International Journal of Heat and Mass Transfer, 2018. 125: p. 218-228.

5. Macriss, R.A., J. Gutraj, and T. Zawacki, Absorption fluids data survey: final report on worldwide data. 1988, Oak Ridge National Lab., TN (USA); Institute of Gas Technology, Chicago, IL (USA).

6. Joudi, K.A. and A.H. Lafta, Simulation of a simple absorption refrigeration system. Energy conversion and Management, 2001. 42(13): p. 1575-1605.

7. Kim, D. and C.I. Ferreira, Air-cooled LiBr-water absorption chillers for solar air conditioning in extremely hot weathers. Energy Conversion and Management, 2009. 50(4): p. 1018-1025.

8. Gebreslassie, B.H., M. Medrano, and D. Boer, Exergy analysis of multi-effect water$\mathrm{LiBr}$ absorption systems: from half to triple effect. Renewable energy, 2010. 35(8): p. $1773-1782$.

9. Liu, Y. and R. Wang, Performance prediction of a solar/gas driving double effect LiBr-H 2 O absorption system. Renewable Energy, 2004. 29(10): p. 1677-1695.

10. Arun, M., M. Maiya, and S.S. Murthy, Performance comparison of double-effect parallel-flow and series flow water-lithium bromide absorption systems. Applied thermal engineering, 2001. 21(12): p. 1273-1279.

11. Arun, M., M. Maiya, and S.S. Murthy, Equilibrium low pressure generator temperatures for double-effect series flow absorption refrigeration systems. Applied thermal engineering, 2000. 20(3): p. 227-242.

12. Xu, G. and Y. Dai, Theoretical analysis and optimization of a double-effect parallelflow-type absorption chiller. Applied thermal engineering, 1997. 17(2): p. 157170.

13. Walter Ambrosini, N.F., Francesco Oriolo, Caroline Dannoehl, \& Holger J Konle, Experiments and CFD analyses on condensation heat transfer in a square cross section channel. 11 international topical meeting on nuclear reactor thermal hydraulics (Nureth 11), France, 2005. 
14. Ustinenko, V., et al., Validation of CFD-BWR, a new two-phase computational fluid dynamics model for boiling water reactor analysis. Nuclear Engineering and Design, 2008. 238(3): p. 660-670.

15. Krepper, E., B. Končar, and Y. Egorov, CFD modelling of subcooled boilingConcept, validation and application to fuel assembly design. Nuclear Engineering and Design, 2007. 237(7): p. 716-731.

16. Abedini, E., et al., Experimental investigation and comparison of subcooled flow boiling of TiO2 nanofluid in a vertical and horizontal tube. Proceedings of the Institution of Mechanical Engineers, Part C: Journal of Mechanical Engineering Science, 2013. 227(8): p. 1742-1753.

17. Colburn, A.P. and O.A. Hougen, Design of Cooler Condensers for Mixtures of Vapors with Noncondensing Gases. Industrial \& Engineering Chemistry, 1934. 26(11): p. 1178-1182.

18. Li, J.-D., CFD simulation of water vapour condensation in the presence of noncondensable gas in vertical cylindrical condensers. International Journal of Heat and Mass Transfer, 2013. 57(2): p. 708-721.

19. PADOIN, N. and C. SOARES, CFD MODELING OF STEAM CONDENSATION IN INDUSTRIAL PIPES. Blucher Chemical Engineering Proceedings, 2015. 1(2): p. 12904-12911.

20. Sun, D., J. Xu, and Q. Chen, Modeling of the Evaporation and Condensation PhaseChange Problems with FLUENT. Numerical Heat Transfer, Part B: Fundamentals, 2014. 66(4): p. 326-342.

21. Mimouni, S., et al., CFD Modeling of Wall Steam Condensation: Two-Phase Flow Approach versus Homogeneous Flow Approach. Science and Technology of Nuclear Installations, 2011. 2011.

22. Nabati, H., Investigation on Numerical Modeling of Water Vapour Condensation from a Flue Gas with High COR2R Content. Energy and Power Engineering, 2011. Vol.03No.02: p. 9.

23. Hiller, R.A. and G.W. Swift, Condensation in a steady-flow thermoacoustic refrigerator. The Journal of the Acoustical Society of America, 2000. 108(4): p. 1521-1527.

24. Laguerre, O., S. Benamara, and D. Flick, Study of water evaporation and condensation in a domestic refrigerator loaded by wet product. Journal of Food Engineering, 2010. 97(1): p. 118-126.

25. Gao, L., et al. The Numerical Simulation of Flow and Boiling Heat Transfer of Two Phases in Horizontal Tube. in 2012 Asia-Pacific Power and Energy Engineering Conference. 2012.

26. Trujillo, F.J., et al. CFD modeling of the heat and mass transfer process during the evaporation of water from a circular cylinder. in 3rd Int. Conference on CFD in the Minerals and Process Ind., CSIRO. 2003.

27. Vik, T. and B.A.P. Reif, Implementation of a new and improved evaporation model in Fluent. Forsvarets forskningsinstitutt, Kjeller, Norway, FFI-rapport, 2011. 116.

28. Yang, Z., X. Peng, and P. Ye, Numerical and experimental investigation of two phase flow during boiling in a coiled tube. International Journal of Heat and Mass Transfer, 2008. 51(5): p. 1003-1016.

29. Chyu, M.C. and A.E. Bergles, An Analytical and Experimental Study of Falling-Film Evaporation on a Horizontal Tube. Journal of Heat Transfer, 1987. 109(4): p. 983990.

30. Fujita, Y. and M. Tsutsui, Evaporation heat transfer of falling films on horizontal tube. Part 2: Experimental study. Heat Transf. Jpn. Res., 24, 1995: p. 17-31.

31. Fujita, Y. and M. Tsutsui, Experimental investigation of falling film evaporation on horizontal tubes. Heat Transf. Jpn. Res., 27, 1998: p. 609-618.

32. Mitrovic, J., Influence of tube spacing and flow rate on heat transfer from a horizontal tube to a falling liquid film, in eighth international heat transfer conference. Volume (4). 1986: San Francisco, USA. p. 1949-1956. 
33. Parken, W.H., Heat transfer to thin water films on horizontal tubes, in Fluid Mechanics and Heat Transfer. 1975, Ph.D. Thesis Rutgers Univ., New Brunswick, NJ.

34. Yang, L. and S. Shen, Experimental study of falling film evaporation heat transfer outside horizontal tubes. Desalination, 2008. 220(1): p. 654-660.

35. Armbruster, R. and J. Mitrovic, Heat transfer in falling film on a horizontal tube, in Proceeding of the national heat transfer conference, . 1995: Portland, Vol. 12, 1995 [ASME HTD-vol. 314], p. 13-21.

36. LEE, W.H., A Pressure Iteration Scheme for Two-Phase Flow Modeling in T. N. Veziroglu (ed.). Multiphase Transport Fundamentals, Reactor Safety, Applications, 1980.

37. Jasper, J.J., The surface tension of pure liquid compounds, . 1972: J. Phys. Chem. Ref. Data 1, 841-1010.

38. Fluent-Solver, A., Theory Guide. Release I, 2013.

39. Guide, A.F.U.s., Version 15. ANSYS Inc., January, 2013.

40. Dehbi, A. and S. Guentay, A model for the performance of a vertical tube condenser in the presence of noncondensable gases. Nuclear Engineering and Design, 1997. 177(1-3): p. 41-52.

41. Shao, D.W. and E. Granryd, Experimental and theoretical study on flow condensation with non-azeotropic refrigerant mixtures of R32/R134a. International Journal of Refrigeration, 1998. 21(3): p. 230-246. 